\title{
The foliar water relations in orange plants (Citrus sinensis L.) are affected by sooty mold
}

\author{
P. Insausti ${ }^{1,2}$ and E.L. Ploschuk ${ }^{3}$ \\ ${ }^{1}$ Cátedra de Fruticultura, FAUBA, Av. San Martín 4453, C1417DSE Buenos Aires, Argentina \\ ${ }^{2}$ IFEVA-Facultad de Agronomía, UBA-CONICET, Av. San Martín 4453, C1417DSE Buenos Aires, Argentina \\ ${ }^{3}$ Cátedra de Cultivos Industriales, FAUBA, Av. San Martín 4453, C1417DSE Buenos Aires, Argentina
}

\begin{abstract}
Summary
Sooty molds are a lineage of foliar fungi that is located on the surface of the leaf and does not penetrate the cuticle. The aim of this study was to evaluate changes in the temperature of the leaves of orange plants due to the increased absorption capacity of long-wave radiation caused by the black colour of the sooty mold mycelia and to investigate how this response affects the foliar water relations. Leaves of orange trees with and without sooty mold were evaluated: leaf temperature, vapor pressure difference (VPD) between the leaf and the atmosphere, stomatal conductance, water potential, leaf transpiration, photosynthesis and instantaneous water use efficiency (WUEI). Leaf temperature, VPD and transpiration were higher in leaves with sooty mold. However, stomatal conductance, net photosynthesis and water potential were not affected. The consequence of these responses is the lower WUEI of leaves with sooty mold increasing the water cost for each $\mathrm{CO}_{2}$ molecule fixed.
\end{abstract}

\section{Keywords}

Citrus, fungi mycelia, leaf temperature, stomatal

conductance, water potential, water-use efficiency

\section{Introduction}

When fungi pathogens invade a leaf, they can either pass through the stomatal pores or breach the cuticle. Infections can occur within the substomatal cavity and affect stomatal function (Grimmer et al., 2012). According to these authors, the deleterious effects of fungi on WUEI have also been demonstrated in a number of pathosystems. Interference with the opening of the stomata under illumination has implications for the ability of the affected plant to assimilate $\mathrm{CO}_{2}$ for photosynthesis. Furthermore, breaches of the cuticle by fungi pathogens and the impairment of stomatal closing in the dark have implications for the ability to retain water (Grimmer et al., 2012).

However, another type of leaf fungi located on the surface of the leaf can affect the water relations of the plant without directly affecting the host. The growth of fungal mycelium on the leaf surface in a non-parasitic relationship is a common type of epiphytic phenomenon (Lemos Filho and Paiva, 2006). Sooty mold is a general term applied to several hundred species that are unified as a fungal guild by the characteristics of a living plant surface habitat, on which they exclusively occur and an ever present, darkly pigmented cell wall (Reynolds, 1999). Sooty molds are foliicolous fungi, which grow on the adaxial surface of leaves, stems and fruits, at the expense of

\section{Significance of this study}

What is already known on this subject?

- The growth of sooty mold mycelium on the leaf surface is a common type of epiphytic phenomenon in orange leaves. Sooty mold causes increase of leaf temperature in other species.

\section{What are the new findings?}

- Sooty mold can affect leaf transpiration and the instantaneous water use efficiency (WUEI) by simply modifying the heat absorption and temperature properties of the leaves without affecting their integrity.

What is the expected impact on horticulture?

- Transpiration was higher in leaves with sooty mold. However, net photosynthesis was not affected. The consequence of these responses is the lower WUEI of leaves with sooty mold, increasing the water cost for each $\mathrm{CO}_{2}$ molecule fixed. WUEI constitutes an important measure of the sustainability of the production in irrigated and non-irrigated fruit orchards.

sugary excretions that some insects deposit on these organs (Reynolds, 1999). The insects excrete honeydew as a waste product. The sooty molds grow on this and produce a thin superficial network of dense, dark hyphae (Hughes, 1976; Chomnunti et al., 2014). Although sooty mold could result in detrimental effects in citriculture from a quality perspective, such as fruit appearance, the fungal black mycelia have no negative effect on the photosynthesis of orange leaves (Insausti et al., 2015). The sooty molds reported from Citrus include a complex of fungi of several genera (Reynolds, 1999; Santos et al., 2013). However, Capnodium species are the most commonly found sooty molds (Reynolds, 1999; Chomnunti et al., 2014). The accumulation of a fungal mat on the adaxial surface does not cause physical injury to the leaf but has the potential to reduce sunlight penetration (Wood et al., 1988; Lemos Filho and Paiva, 2006); moreover, the reflected wavelengths of the electromagnetic spectrum are altered (Summy and Little, 2008), increasing the temperature of the leaf (Wood et al., 1988). The dark film produced by sooty mold causes a greater absorption of long-wave radiation than that found in leaves without sooty mold and also produces a higher temperature in the leaf on which the mold grows. In pecan, the presence of sooty mold produces a $4^{\circ} \mathrm{C}$ increase in the temperature of the leaf (Wood et al., 1988). These authors state that the greater heating of the leaf pro- 
duced by the black film associated with the fungus is due to the greater absorption of radiant energy by the black body. They also argue that the higher temperature of a leaf with sooty mold may increase respiration and thus potentially affect the net balance of $\mathrm{CO}_{2}$. However, no previous studies have investigated the effect of the heating of the leaf produced by sooty mold on the increased transpiration of the leaves and its consequences for the water potential, stomatal conductance and efficiency of water use.

In Citrus, the stomatal sensitivity to temperature is very low between $25^{\circ} \mathrm{C}$ and $40^{\circ} \mathrm{C}$ (Machado et al., 2005). Normally, a decrease in the leaf water potential is caused by an increase in transpiration in response to a deficiency of water vapor pressure between the leaf and the air (Cohen and Cohen, 1983; Syvertsen and Lloyd, 1994; Nobel, 2005). This response may underlie the subsequent stomatal closure, although this phenomenon occurs in Citrus at relatively high atmospheric demand levels (Ribeiro and Machado, 2007), and in response to vapor pressure difference (Ribeiro et al., 2009), an ABA-mediated mechanism in the leaf (Lambers et al., 2008). Moreover, Citrus plants show anisohydric behaviour (Ribeiro and Machado, 2007) and therefore do not have strict stomatal control. They are characterised by significant water potential decreases throughout the day in response to water imbalances in the plant (Tardieu and Simonneau, 1998).

The aim of this paper was to evaluate changes in the temperature of the leaves of orange plants due to the increased absorption capacity of long-wave radiation caused by the black colour of the sooty mold mycelia and to investigate how this response may influence water relations through its direct effect on leaf transpiration.

We specifically addressed the following questions: (1) How does the black film produced by sooty mold mycelia affect the leaf temperature in orange plants? (2) Do changes in temperature affect the leaf transpiration rate due to its direct influence on the deficit of water vapor pressure between the leaf and the atmosphere? (3) Are the water potential and stomatal conductance values different in leaves with and without sooty mold if both are exposed to the sun? (4) What is the effect of this foliar fungus on water use efficiency, given that its effect is due only to changes in the absorption of longwave radiation in the presence of increased heating of the sooty mold-leaf system?

\section{Materials and methods}

\section{Plant material and experimental design}

Ten-year-old trees (Citrus sinensis L. cv. Washington Navel) were sampled from an orange grove located in the experimental fruit orchard of the University of Buenos Aires (Argentine) ( $\left.34^{\circ} 35^{\prime} \mathrm{S}, 58^{\circ} 29^{\prime} \mathrm{W}\right)$. Five plants with similar characteristics (age, height, handling, health status, etc.), were randomly selected for this study. Some leaves presented an intense fungal infestation and others were completely free of sooty mold (Figure 1). As the trees had leaves presenting different levels of sooty mold infestation, only leaves severely infested were chosen. All plants were irrigated regularly during the experiment.

For each of the five experimental plants, measurements were carried out on leaves with and without sooty mold, establishing the following measuring conditions: (1) Reference leaves: not infested by sooty mold. (2) Leaves with sooty mold: those covered by a dark mycelia on the adaxial side with similar visually estimated thickness and degree of cov- erage. At the time of the measurements, it was estimated that the area affected per tree was $40-50 \%$.

The data were generated from two years (2013-2014) and two sites in the experimental fruit orchard with the same results. Only year data and site are shown.

\section{Leaf temperature measurements}

The influence of sooty mold on leaf temperature was evaluated by comparing the surface temperatures of moldfree leaves with the surface temperatures of mold-infested leaves. Temperature measurements were made on the abaxial surface (shaded side) of 10 leaves from each tree and treatment with minithermistors PTC, $100 \mathrm{~K}^{\prime} \Omega$ at $25^{\circ} \mathrm{C}$, Vishay no. 91102 (Vishay Electronic, Selb, Germany) apprised to the leaf surface at noon at the time of maximum PAR daily during one week in March (2014).

\section{Water vapor pressure difference between leaf substomatal cavity and atmosphere (VPD)}

We considered the difference between the saturation vapor pressure at the leaf temperature and the atmosphere actual water vapor pressure at the ambient air temperature in measuring this trait. Ten leaves with sooty mold and ten reference leaves from each tree were used for the calculation, and five tree replicate measurements were made during one week in March 2014.

The VPD was calculated according to the following equations:

$$
\mathrm{e}=\mathrm{e}_{\mathrm{sa}} * \mathrm{RH}
$$$$
\mathrm{VPD}=\left(\mathrm{e}_{\mathrm{sl}}-\mathrm{e}\right)
$$

where e is the vapor pressure of the air $(\mathrm{KPa})$; $\mathrm{e}_{\mathrm{sa}}$ is the saturated vapor pressure $(\mathrm{KPa})$ in the air at the ambient temperature; $\mathrm{e}_{\mathrm{sl}}$ is the vapor pressure $(\mathrm{KPa})$ in the substomatal chamber (the concentration of water vapor in the substomatal chamber was considered similar to that of saturated air at the leaf temperature (Lambers et al., 2008)) and RH is the relative humidity of the ambient air (\%). The saturated vapor pressure $\left(\mathrm{e}_{\mathrm{sa}}\right.$ and $\left.\mathrm{e}_{\mathrm{sl}}\right)$ values were taken from saturated vapor pressure tables at different temperatures (Brown and Van Haveren, 1972).

The leaf temperature values were recorded according to the methodology described above with the same device, and ambient temperature and relative humidity was recorded by a Davis Instruments Vantage Pro 2 automatic weather station, located in the experimental fruit orchard.

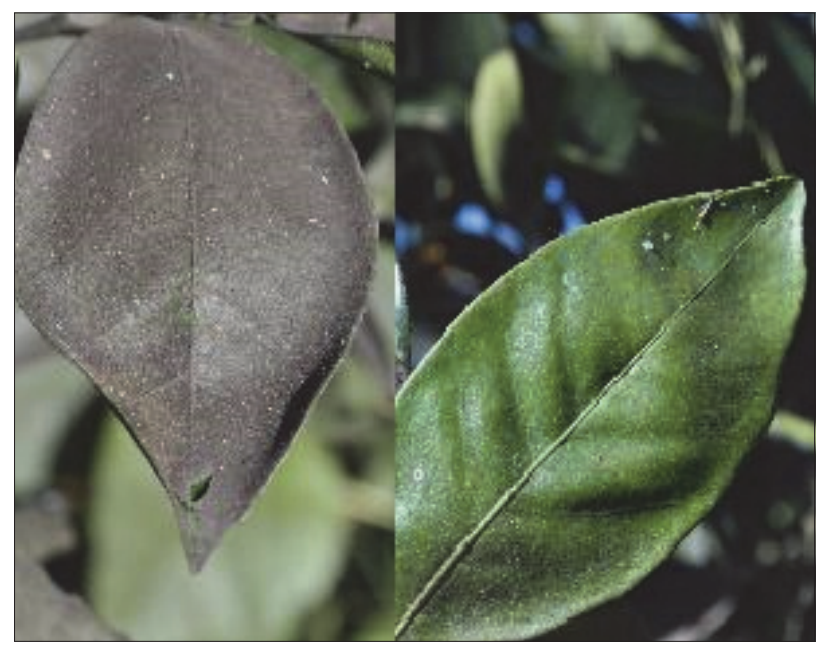

FIGURE 1. Representative samples of a leaf infested by sooty mold and without sooty mold. 
TABLE 1. Leaf temperature $\left({ }^{\circ} \mathrm{C}\right.$ ) and vapor pressure difference (VPD) (KPa) between leaves and atmosphere, in leaves with and without sooty mold (reference) $(n=10)$. SE indicates standard error of the means. Significant differences were observed on all seven days of evaluation ( $\mathrm{p}<0.0001$ in each day).

\begin{tabular}{lclllclcc}
\hline \multirow{2}{*}{ Days } & \multicolumn{2}{c}{ Reference } & \multicolumn{2}{c}{ Sooty mold } & \multicolumn{2}{c}{ Reference } & \multicolumn{2}{c}{ Sooty mold } \\
\cline { 2 - 9 } & Temp. $\left({ }^{\circ} \mathrm{C}\right)$ & SE & Temp. $\left({ }^{\circ} \mathrm{C}\right)$ & SE & VPD (KPa) & SE & VPD $(\mathrm{KPa})$ & SE \\
\hline 1 & 24.9 & 0.17 & 30 & 0.2 & 1.88 & 0.02 & 2.98 & 0.03 \\
2 & 25.1 & 0.14 & 30.1 & 0.19 & 1.84 & 0.01 & 2.83 & 0.04 \\
3 & 24.9 & 0.14 & 30 & 0.17 & 1.88 & 0.03 & 3 & 0.02 \\
4 & 25 & 0.14 & 29.9 & 0.14 & 1.75 & 0.02 & 2.96 & 0.02 \\
5 & 25 & 0.13 & 30 & 0.13 & 1.75 & 0.04 & 2.82 & 0.01 \\
6 & 25.1 & 0.11 & 30.1 & 0.16 & 1.75 & 0.03 & 2.91 & 0.02 \\
7 & 25 & 0.12 & 30 & 0.2 & 1.84 & 0.02 & 2.95 & 0.01 \\
\hline Mean & 25 & 0.03 & 30 & 0.03 & 1.81 & 0.02 & 2.92 & 0.02 \\
\hline
\end{tabular}

\section{Stomatal conductance and water potential}

Stomatal conductance was measured on the above mentioned leaves with a model AP4 Delta-T diffusion porometer (Delta-T Devices, Cambridge). The PAR solar radiation was recorded at the time of the measurement with a Li-Cor $\mathrm{Q}$ radiation sensor (Li-Cor Inc., Lincoln, Nebraska). Measurements were made during one week at midday at the time of maximum PAR radiation on a clear day. On the same leaves at which stomatal conductance was assessed, leaf water potential was measured immediately with a pressure chamber (Scholander pump) Biocontrol, model 4 (Bio-control, Argentina).

\section{Net photosynthesis and leaf transpiration}

Net photosynthesis and leaf transpiration were measured, the last day on 10 leaves chosen at random for each of the above treatments with a portable LI-COR 6400 IRGA (LiCor Inc., Lincoln, Nebraska) under $1600 \mathrm{mmol} \mathrm{m}^{-2} \mathrm{~s}^{-1}$ PPFD. Saturating light was provided by the 6400-40 leaf chamber using a mix of $80 \%$ red and $20 \%$ blue light. The measuring flow was set at $300 \mu \mathrm{mol} \mathrm{s}^{-1}$, with $\mathrm{CO}_{2}$ concentration fixed in the reference cell at $400 \mathrm{ppm}$.

\section{Instantaneous water-use efficiency (WUEI)}

We estimated this variable as the ratio of the light-saturated net $\mathrm{CO}_{2}$ assimilation to the transpiration rate at the leaf level (Polley, 2002; Cabrera-Bosquet et al., 2007; Grimmer et al., 2012).

\section{Statistical analysis}

The data were analysed using the InfoStat statistical software (Di Rienzo et al., 2013). The effects on the week measurements were evaluated by repeated measures analysis of variance (rmANOVA) (Moser et al., 1990). Data in the last day were tested for any differences between treatments using Student's $t$-test. Differences were considered significant when $\mathrm{p}<0.05$. Data from table and figures represent averages and standard errors of the means (mean $\pm \mathrm{SE}$ ). The assumptions of homogeneity of variance and normality of the data had previously been validated with Levene and Shapiro-Wilk tests, respectively.

\section{Results}

\section{Leaf temperature and vapor pressure difference} between leaves and atmosphere

The leaves covered by the dark film of sooty mold showed a higher temperature than the leaves without the fungus.
This difference was observed on all seven days of evaluation (Table 1) ( $p<0.0001$ in each day). On leaves with sooty mold, the mean of temperature was almost $5^{\circ} \mathrm{C}$ higher than on those with no sooty mold (Table 1).

Given the differences in foliar temperature, a higher VPD between the leaves and the atmosphere was recorded for the sooty mold treatment than for the leaves without sooty mold (Table 1) $(\mathrm{p}<0.0001$ in each day).

\section{Stomatal conductance and water potential}

No significant differences were found in stomatal conductance between the leaves with sooty mold and reference leaves without the fungus on any day of the week $(\mathrm{p}<0.01)$ (Figure 2). No significant differences between treatments

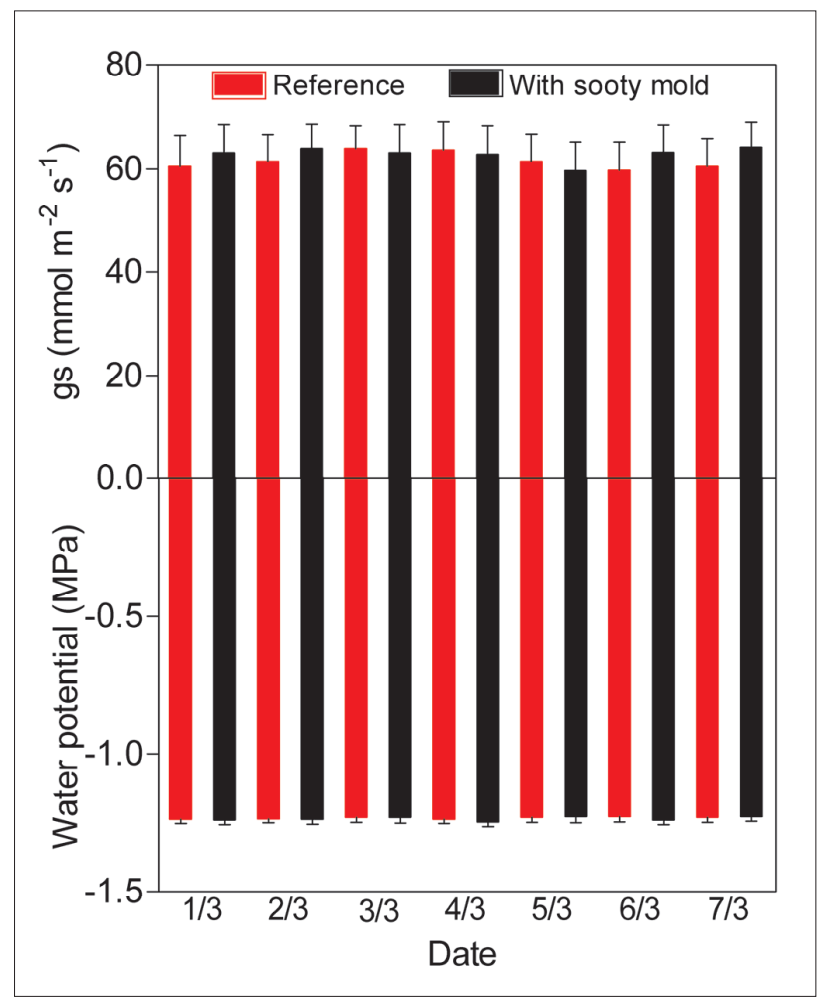

FigURE 2. Stomatal conductance (gs) and water potential in leaves with and without sooty mold (reference) evaluated on a clear day with high PAR radiation during one week $(n=5)$. Bars indicate standard error. No significant differences were found in both variables between the leaves with sooty mold and reference leaves without the fungus on any day of the week $(\mathrm{p}<0.01)$. 
were found from the measurements of water potential in the same leaves at the same dates $(\mathrm{p}<0.005)$ (Figure 2).

\section{Leaf transpiration and photosynthesis}

A higher transpiration rate $(\mathrm{p}<0.005)$ was recorded in the leaves covered with sooty mold than in the leaves without the black film (Figure 3a). The infested leaves transpired $73.4 \%$ more than the reference leaves. However, no significant differences between the sooty mold treatments and references were found for the rate of leaf net photosynthesis measured at midday $(\mathrm{P}=0.62)$, despite the substantial reduction of incident radiation through the leaf surface expected for the infested leaves (Figure 3b).

\section{WUEI}

Because of the significant effect of sooty mold on the transpiration rate and the lack of an effect of the fungus on photosynthesis, the instantaneous water-use efficiency of the leaves with sooty mold was significantly lower than that of the reference leaves (Figure 3c).

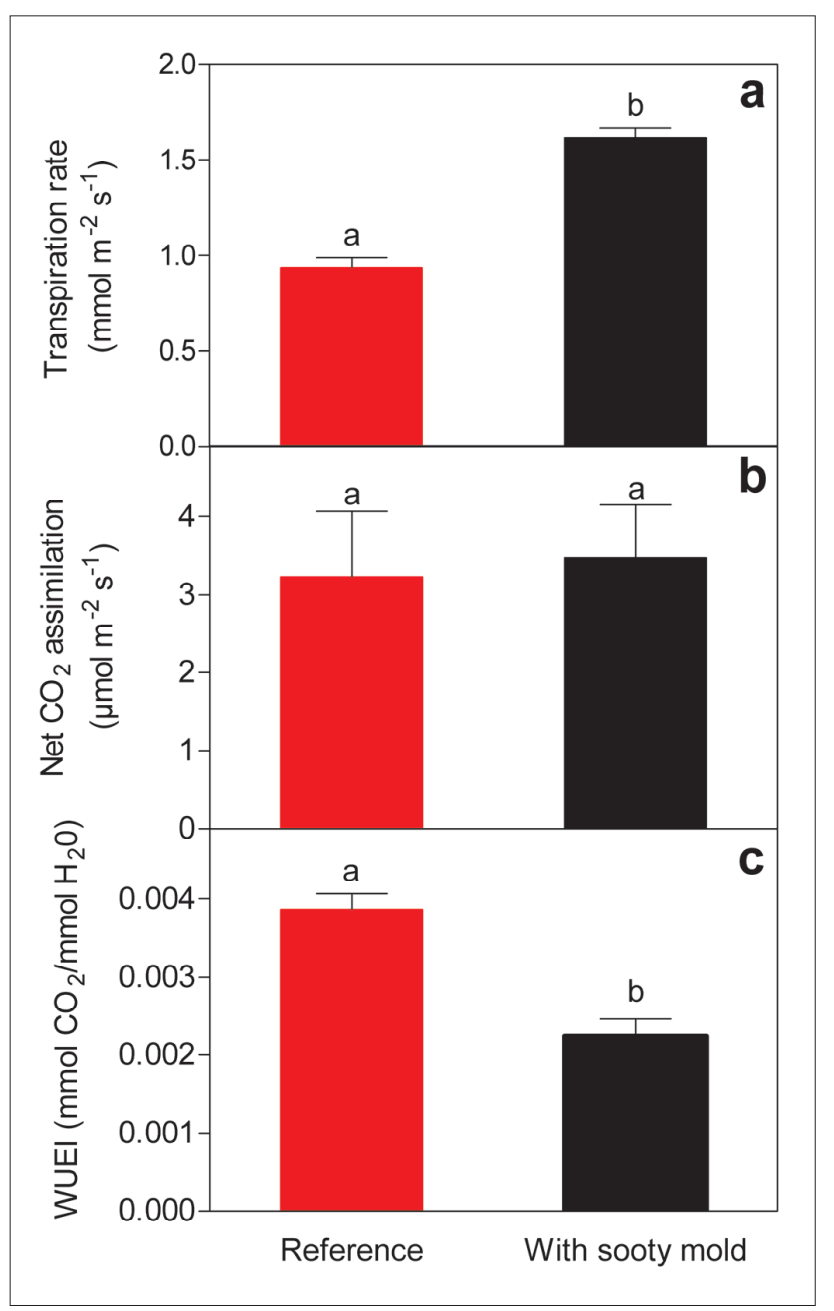

FiguRE 3. Leaf transpiration rate (a), net photosynthesis (b) and instantaneous water use efficiency (c) in leaves with and without sooty mold (reference), evaluated the last day under $1600 \mathrm{mmol} \mathrm{m}^{-2} \mathrm{~s}^{-1}$ PPFD $(n=10)$. Different letters indicate significant differences between treatments.

\section{Discussion}

Sooty mold, an epiphytic complex of fungi, grows only on the leaf surface without passing through the cuticle or affecting the mesophyll or stomata (Hughes, 1976; Lemos Filho and Paiva, 2006; Chomnunti et al., 2014). However, sooty molds are associated with sap-sucking insects that affect yield and quality in orange plants (Timmer et al., 2001; Chomnunti et al., 2014). According to our results, the black mycelia caused by the sooty mold fungus is a factor that modifies the leaf temperature (Table 1). This effect would be a consequence of the increased radiation absorption properties of the leaves due to the black film produced by the fungus, as a black body absorbs more light because it transmits or reflects less of it (Serway et al., 2005). It is well known that an increase in temperature in the leaves is involved in changes in VPD (Table 1) and transpiration (Figure 3) and therefore in the water balance (Lambers et al., 2008). In agreement with the findings of Wood et al. (1988) for pecan plants, the orange leaves covered with sooty mold had a temperature $5^{\circ} \mathrm{C}$ higher than the reference leaves (Table 1). This effect was caused by the greater absorption of radiant energy by the leaves with black fungus. The recorded increase in VPD between the leaf and the atmosphere was the result of the increased temperature of the leaf (Nobel, 2005; Lambers et al., 2008). Therefore, the increase in transpiration recorded in the leaves with sooty mold was exclusively a consequence of the increase in VPD, as the resistance to water vapor flux was not affected. For a wide range of pathosystems, it has been shown that the stomatal aperture size in the light is reduced compared with healthy references (Grimmer et al., 2012). However, our results showed that the sooty mold did not affect the functioning of the stomata (Figure 2). In this context, note that the stomata in orange plants are preferentially located on the opposite side of the leaf from the site of the sooty mold infestation.

However, although transpiration is a vital component of water balance (Lambers et al., 2008), the water potential was not affected in the leaves with sooty mold (Figure 2), although they had a higher rate of transpiration. The anisohydric behaviour of citrus plants is well known (Ribeiro and Machado, 2007). This behaviour implies that they do not control stomatal conductance very precisely and, therefore, show significant decreases in the water potential throughout the day in response to water imbalances in the plant (Tardieu and Simonneau, 1998). However, such decreases did not occur in our study, perhaps because there was no water restriction in the soil.

Foliar pathogens affect the water relations of plants, and this effect has implications on water-use efficiency (WUEI) (Grimmer et al., 2012). WUEI constitutes an important measure of the sustainability of crop production, depending both on cuticular integrity and the normal guard cell regulation of the stomatal aperture in response to solar radiation, the partial pressure of $\mathrm{CO}_{2}$, and water availability (Condon et al., 2004). Grimmer et al. (2012) state that a range of foliar pathogens have been shown to disrupt the stomatal regulation of transpiration and gas exchange. The effects are a consequence of the spread of the fungus within the mesophyll through the cuticle and stomata, and the damage produced has deleterious effects on the instantaneous water-use efficiency (WUEI). However, these factors were not involved in the lower WUEI of leaves with sooty mold.

According to our results and previous study (Insausti et al., 2015), the sooty mold mycelia did not affect net photosynthesis (Figure 3) despite the substantial reduction in the incident radiation through the leaf surface expected 
in the presence of the black film. It is known that citrus show acclimation to shade and traits that are adaptive to low solar radiation (Syvertsen and Smith, 1984; Syvertsen and Lloyd, 1994; Ribeiro et al., 2009). Part of the ability of citrus to acclimate to shade is due to the higher content of chlorophyll in shaded leaves. It would cause an increase in radiation conversion to photosynthesis (quantum yield) under conditions of low PPFD in the shade (Syvertsen and Smith, 1984; Syvertsen and Lloyd, 1994; Ribeiro et al., 2009). Insausti et al. (2015) state that orange leaves can acclimate to a lower PPFD produced by sooty mold in the same way as for conventional shading processes. Thus, the sooty mold mycelia behaved as a physical light interceptor, with an effect similar to that produced by shade. Carbon assimilation did not differ between the leaves with sooty mold and the references, so that the changes in WUEI (Figure 3) were only produced by the effect on transpiration. However, a great number of leaves were not exposed to sunlight. It is probable that the photosynthetic characteristics of these leaves differed from those of the exposed leaves (Ribeiro and Machado, 2007). Therefore, although the higher leaf temperature and the water vapor pressure difference between the leaves with sooty mold and the atmosphere may help to predict lower water efficiency in crops with sooty mold, this hypothesis should be tested throughout the canopy.

\section{Conclusion}

This study demonstrates that the sooty mold black film on the leaves of orange trees affects hydric variables. Sooty mold can affect leaf transpiration by simply modifying the heat absorption and temperature properties of the leaves without affecting their integrity. However, net photosynthesis was not affected. The consequence of these responses is the lower WUEI of leaves with sooty mold, increasing the water cost for each $\mathrm{CO}_{2}$ molecule fixed.

\section{References}

Brown, R.W., and Van Haveren, B.P. (1972). Appendix I: Saturated Vapor Pressure. In Psychrometry in Water Relations Research, R.W. Brown, and B.P. Van Haveren, eds. (Logan, Utah, USA: Utah State University), p. 266-271.

Cabrera-Bosquet, L., Molero, G., Bort, J., Nogues, S., and Araus, J.L. (2007). The combined effect of constant water deficit and nitrogen supply on WUE, NUE and D13 C in durum wheat potted plants. Ann. Appl. Biol. 151, 277-289. https://doi.org/10.1111/j.17447348.2007.00195.x

Chomnunti, P., Hongsanan, S., Aguirre-Hudson, B., Tian, Q., Peršoh, D., Dhami, M.K., Alias, A.S., Xu, J., Liu, X., Stadler, M., and Hyde, K.D. (2014). The sooty moulds. Fungal Diversity 66, 1-36. https://doi. org/10.1007/s13225-014-0278-5.

Cohen, S., and Cohen, Y. (1983). Field studies of leaf conductance response to environmental variables in citrus. J. Appl. Ecol. 20, 561570. https://doi.org/10.2307/2403526.

Condon, A.G., Richards, R.A., Rebetzke, G.J., and Farquhar, G.D. (2004). Breeding for high water-use efficiency. J. Exp. Bot. 55, 2447-2460. https://doi.org/10.1093/jxb/erh277.

Di Rienzo, J.A., Casanoves, F., Balzarini, M.G., Gonzalez, L., Tablada, M. and Robledo, C.W. (2013). Info Stat. URL http://www.infostat.com.ar (verified Dec. 3, 2017)

Grimmer, M.K., Foulkes, M.J., and Paveley, N.D. (2012). Foliar pathogenesis and plant water relations: a review. J. Exp. Bot. 63, 4321-4331. https://doi.org/10.1093/jxb/ers143.
Hughes, S.J. (1976). Sooty moulds. Mycologia 68, 693-820. https:// doi.org/10.2307/3758799.

Insausti, P., Ploschuk, E.L., Izaguirre, M.M., and Podworny, M.G. (2015). The effects of sunlight interception by sooty mold on chlorophyll content and photosynthesis in orange leaves (Citrus sinensis L.). Eur. J. Plant Pathol. 143, 559-565. https://doi.org/10.1007/s10658-0150709-5.

Lambers, H., Stuart, F.C., and Pons, T.L. (2008). Plant water relations. In Plant Physiological Ecology, H. Lambers, ed. (New York, USA: Springer), p. 154-209. https://doi.org/10.1007/978-0-387-7834135 .

Lemos Filho, J.P., and Paiva, E.A. (2006). The effects of sooty mold on photosynthesis and mesophyll structure of mahogany. Bragantia 65, 11-17. https://doi.org/10.1590/S0006-87052006000100003.

Machado, E.C., Schmidt, P.T., Medina, C.L., and Ribeiro, R.V. (2005). Photosynthetic responses of three citrus species to environmental factors. Pesqui. Agropecu. Bras. 40, 1161-1170. https://doi. org/10.1590/S0100-204X2005001200002.

Moser, E.B., Saxton, A.M., and Pezeshki, S.R. (1990). Repeated measures analysis of variance: application to tree research. Can. J. For. Res. 20, 524-535. https://doi.org/10.1139/x90-069.

Nobel, P.S. (2005). Water. In Physicochemical and Environmental Plant Physiology, P.S. Nobel, ed. (San Diego, USA: Academic Press), p. 36-80. https://doi.org/10.1016/B978-012520026-4/50003-2.

Polley, H.W. (2002). Implications of atmospheric and climatic change for crop yield and water use efficiency. Crop Sci. 42, 131-140. https://doi.org/10.2135/cropsci2002.1310.

Reynolds, D.R. (1999). Capnodium citri: The sooty mold fungi comprising the taxon concept. Mycopathologia 148, 141-147. https://doi.org/10.1023/A:1007170504903.

Ribeiro, R.V., and Machado, E.C. (2007). Some aspects of citrus ecophysiology in subtropical climates: re-visiting photosynthesis under natural conditions. Braz. J. Plant Phys. 19, 393-411. https:// doi.org/10.1590/S1677-04202007000400009.

Ribeiro, R.V., Machado, E.C., Santos, M.G., and Oliveira, R.F. (2009) Photosynthesis and water relations of well-watered orange plants as affected by winter and summer conditions. Photosynthetica 47 , 215-222. https://doi.org/10.1007/s11099-009-0035-2.

Santos, S.A.P., Santos, C., Silva, S., Pinto, G., Torres, L.M., and Nogueira, A.J.A. (2013). The effect of sooty mold on fluorescence and gas exchange properties of olive tree. Turk. J. Biol. 37, 620-628. https:// doi.org/10.3906/biy-1301-81.

Serway, R.A., Moses, C.J., and Moyer, C.A. (2005). Modern Physics (Belmont, CA: Thomson Learning Inc.)

Summy, K.R., and Little, C.R. (2008). Using color infrared imagery to detect sooty mold and fungal pathogens of glasshouse-propagated plants. HortScience 34, 1485-1491.

Syvertsen, J.P., and Smith, M.L. (1984). Light acclimation in Citrus leaves. I. Changes in physical characteristics, chlorophyll, and nitrogen content. J. Am. Soc. Hortic. Sci. 109, 807-812.

Syvertsen, J.P., and Lloyd, J. (1994). Citrus. In Handbook of Environmental Physiology of Fruit Crops 2, B. Schaffer, and P.C. Andersen, eds. (Boca Raton, USA: CRC Press), p. 65-99.

Tardieu, F., and Simonneau, T. (1998). Variability among species of stomatal control under fluctuating soil water status and evaporative demand: modelling isohydric and anisohydric behaviours. J. Exp. Bot. 49, 419-432. https://doi.org/10.1093/jxb/49.Special_Issue.419.

Timmer, L.W., Garnsey, S.M., and Graham, J.H. (2001). Compendium of Citrus Diseases, (St. Paul, MN, USA: The American Phytopathological Society Press). 
Wood, B.W., Tedders, W.L., and Reilly, C. (1988). Sooty mold fungus on pecan foliage suppresses light penetration and net photosynthesis. HortScience 23, 851-853.

Received: Jun. 6, 2017

Accepted: Feb. 20, 2018

Addresses of authors:

P. Insausti ${ }^{1,2, *}$ and E.L. Ploschuk ${ }^{3}$

${ }^{1}$ Cátedra de Fruticultura, FAUBA, Av. San Martín 4453,

C1417DSE Buenos Aires, Argentina

${ }^{2}$ IFEVA-Facultad de Agronomía, UBA-CONICET, Av. San

Martín 4453, C1417DSE Buenos Aires, Argentina

${ }^{3}$ Cátedra de Cultivos Industriales, FAUBA, Av. San Martín

4453, C1417DSE Buenos Aires, Argentina

* Corresponding author;

Tel. +54+11+4524-8055; Fax: +54+11+4514-8730 